\title{
Cerámica y Arquitectura Pública en el Camino del Inka del Desierto de Atacama (Río Loa, Norte Grande de Chile)
}

\section{Pottery and public settlements at the Inka road of Atacama desert (Loa river, northern Chile)}

Mauricio Uribe R. ${ }^{\text {I }}$ Y Simón Urbina A. ${ }^{2}$

\section{Resumen}

La prehistoria del Norte Grande de Chile se ha construido en gran parte gracias a una arqueología cuya principal fuente de información ha sido la cerámica, por lo menos en el caso de sus periodos agro-alfareros. Este elemento de la cultura material ha recibido una atención que frecuentemente no la han tenido otros aspectos del pasado a pesar de la monumentalidad de muchos restos o el alto potencial de conservación de otros materiales en la zona (p.e., arquitectura, cestería, maderas, textiles, etc.). Siguiendo las principales tendencias del desarrollo de los estudios cerámicos, nuestro propósito en este trabajo es mostrar ciertos lineamientos metodológicos e interpretativos en el tratamiento de la fragmentería cerámica, en términos de sus aplicaciones conceptuales y herramientas analíticas básicas (funcionales, conductuales y contextuales), especialmente relacionadas con las dinámicas sociales y politicas de entidades culturales particulares. Lo anterior se enmarca dentro de un objetivo más amplio que pretende estudiar las materialidades cerámicas y arquitectónicas del periodo Tardio de la región atacameña (14501536 d.C.) para comprender arqueológicamente los procesos socia-

Departamento de Antropología, Facultad de Ciencias Sociales, Universidad de Chile. Av. Cap. Ignacio Carrera Pinto 1045, Nuńoa, Santiago. mur@uchile.cl

2 Licenciado en Antropología con mención en Arqueología. Yerbas Buenas 207, 5110696, Valdivia. simon_ur@hotmail.com

Recibido: Octubre 2007. Aceptado: Junio 2008 
les que desarrollaron sus poblaciones durante el dominio del Inka en el norte de Chile.

Palabras claves: análisis cerámico, arquitectura pública, camino del Inka, Tawantinsuyo, Alto Loa.

\section{Abstract}

The prehistory of northern Chile has been developed by a descriptive archaeology that normally used pottery to reconstruct the agroceramic periods. Great attention has been paid to these items of cultural material unlike other elements of the past, such as big sites and well conserved artifacts of these desert zones (e.g., architecture, basketry, textiles, wooden, etc.). In this sense, pottery has been the main focus of the archaeology as a means to reconstruct the past. Therefore, according to the worldwide tendencies of pottery studies, we will show some methodological and interpretative guidelines in the treatment of this material. We particularity propose some basic concepts and a systematic analysis of the fragmentary debris (functional, behavioral and contextual), as it relates to the social and political dynamics of particular cultures. In a wider context we expect to study the ceramic materials and architecture of the Atacama region during its Late Period (AD 1450-1536) to archaeologically understand the social processes of the local peoples during the Inka domination in northern Chile.

Key words: pottery analysis, public architecture, Inka road, Tawantinsuyo, Alto Loa.

\section{INTRODUCCIÓN}

Sin duda, la prehistoria del Norte Grande de Chile se ha construido en gran parte gracias a una arqueología descriptiva, cuya principal fuente de información ha sido la cerámica, por lo menos en el caso de sus períodos agroalfareros (p.e., Uhle 1919; Latcham 1928). Por lo tanto, este elemento de la cultura material ha recibido una atención de tal envergadura que frecuentemente no la han tenido otros aspectos del pasado a pesar de la monumentalidad de muchos restos o el alto potencial de conservación de otros en la zona (p.e., arquitectura, textiles, cestería, maderas, etc.). En este sentido, la alfarería ha sido un medio privilegiado para la reconstrucción del pasado del desierto más árido del mundo. 
Aprovechando nuevas perspectivas acerca de una importante presencia del Inka (Uribe 1999-2000), lo anterior se enmarca dentro de un objetivo más amplio que pretende analizar las materialidades cerámicas y arquitectónicas del período Tardío (1450-1536 d.C.) de la región atacameña (Figura 1). Nuestro propósito es comprender desde una arqueología tipológica y funcional pero substantiva, la dinámica de los sistemas sociales que desarrollaron sus poblaciones durante el dominio del Inka en la región. De acuerdo a lo anterior, la totalidad de la alfarería fue tratada siguiendo un mismo marco metodológico ya establecido para la región (Varela 1992; Varela et al. 1993; Uribe 1994, 1996, 2004a), cuya aplicación particular a los sitios estudiados da lugar a una caracterización arqueológica más densa del sistema incaico en el Norte Grande y su extensión temporal, así como en sus efectos culturales y sociales.

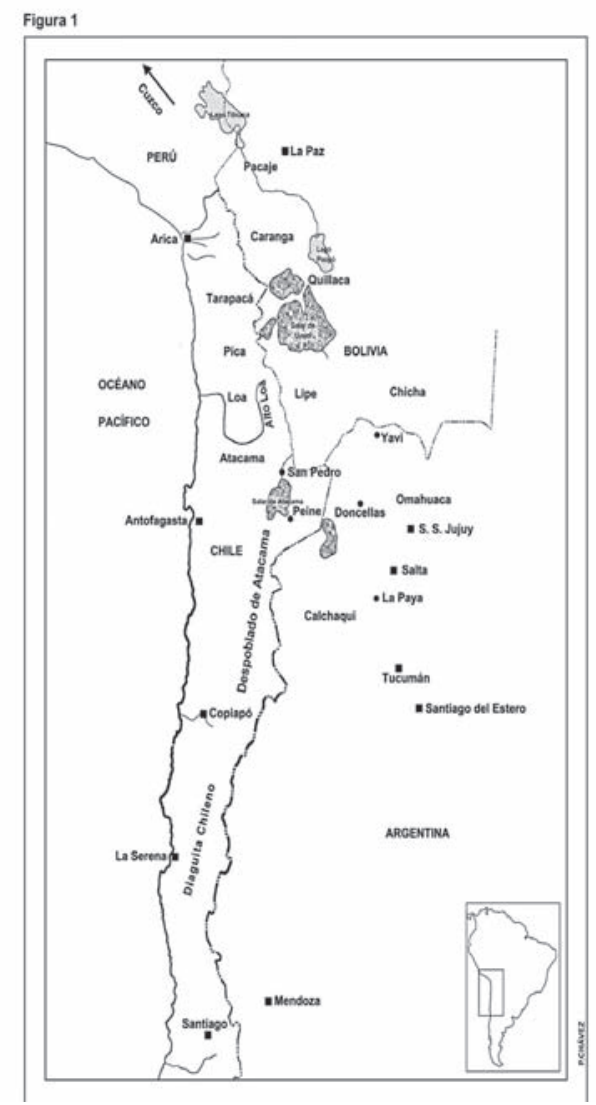

Figura 1. Mapa de los Andes Centro Sur y del Norte de Chile, con las principales localidades mencionadas en el texto (Uribe 2004a).

Figure 1. South-Central Andes locations and prehispanic settlements included in the text (Uribe 2004a). 
Esta caracterización se refiere a la dinámica de la ocupación incaica en la ruta del río Loa a lo largo de 125,07 kilómetros lineales, desde sus nacientes en el volcán Miño hasta Lasana (Berenguer et al. 2005), reflexionando sobre su papel en la prehistoria del desierto de Atacama, en la red de caminos y asentamientos manejada por el Tawantinsuyo. En particular, nos interesa obtener una visión más profunda de los procesos sociales y políticos del Inka en tierras atacameñas, por medio del conocimiento del sistema de circulación y uso de la cerámica y su fragmentería en los asentamientos con arquitectura más importantes del Alto Loa.

\section{Antecedentes}

Nuestro trabajo corresponde a los resultados obtenidos del estudio de la alfarería del Camino del Inka identificado en el curso superior del río Loa, el cual se inserta dentro de un proyecto de investigación del sistema vial del Tawantinsuyo en el sector conocido como Alto Loa ${ }^{1}$ (Figura 2). Al respecto, recientemente hemos informado (Uribe y Cabello 2005) que la identificación tipológica de muestras de superficie y excavación revela que la cerámica más representativa de la ruta corresponde a vasijas no restringidas, sobre todo a escudillas ornitomorfas engobadas o revestidas rojas, las cuales son de manufactura local pero de estilo incaico (Uribe 1999). En los depósitos, éstas se asocian con tipos locales como jarros, aríbalos y escudillas propios del período Tardío, confirmando la relación del camino con el imperio hasta períodos coloniales tempranos, momento en el que se introdujeron nuevas materias primas que terminarían por configurar la actual tradición alfarera de la región (Varela 1992).

Según nuestro primer trabajo (Uribe y Cabello 2005), la ruta habría sido recorrida al menos desde el período Formativo debido a la presencia de alfarería monocroma y pulida de San Pedro de Atacama, entre otras. No obstante, se iniciaría como un verdadero sistema de movilidad durante el Intermedio Tardío, coherente con el énfasis que entonces tuvo el intercambio mediante caravanas de llamas en Atacama (Núñez y Dillehay 1979; Berenguer 2004). Esto se aprecia en nuestro análisis en la clara recurrencia de cerámica propia del desarrollo regional junto con alfarería foránea contemporánea, así como por un arte rupestre local con claras alusiones al tráfico en los asentamientos loínos (Berenguer 2004). 


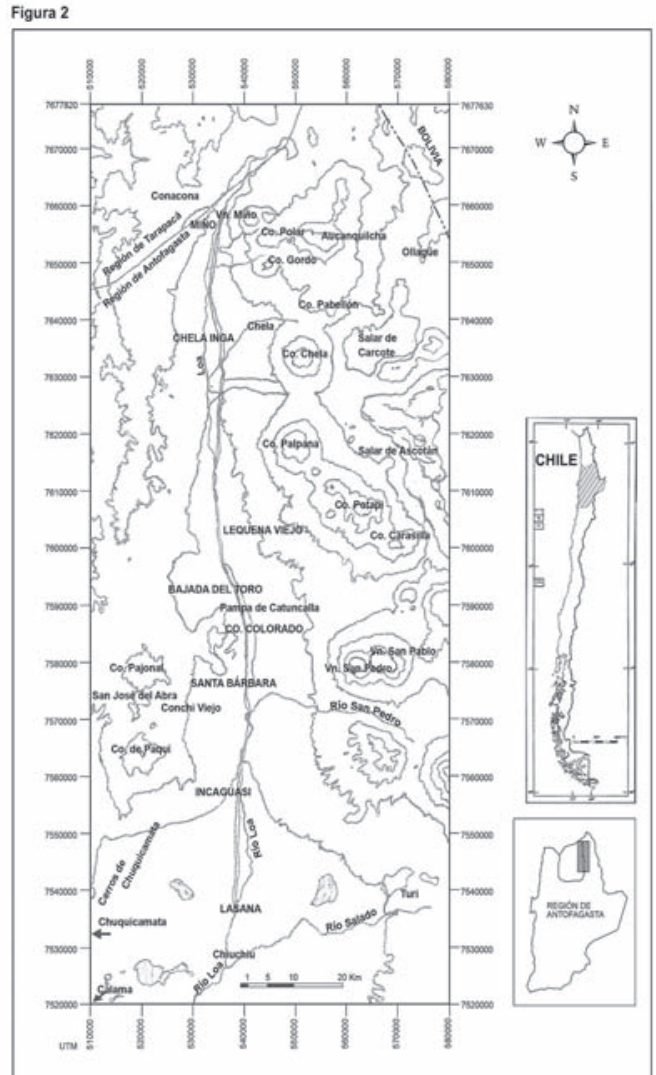

Figura 2. Mapa de la región del Loa Superior y sector del Alto Loa (Norte de Chile), con los principales sitios mencionados en el texto (Berenguer et al. 2005).

Figure 2. Map of the Upper Loa River Region (Northern Chile), and the most important settlements included in the text (Berenguer et al. 2005).

En particular, la ruta privilegiada por el Inka en Alto Loa se puede trazar a partir de las evidencias obtenidas en al menos 18 puntos registrados entre dos tramos a lo largo del río Loa, correspondientes a los tramos Miño-Lequena y Lequena-Lasana (Figura 3 y 4), en cotas que van entre los 4.000 y 3.000 msm respectivamente (Berenguer et al. 2005). En todos ellos destaca una gran presencia de cerámica erosionada, otra clasificada mayoritariamente como escudillas incaicas locales, además de otros tipos incaicos tanto locales como foráneos, que referirían al consumo y servicio de líquidos dada una considerable presencia de platos, cántaros, jarros y/o aríbalos en los asentamientos del camino.

El Inka intervino, seleccionó y remodeló la ruta, ubicando puntos donde se desarrollaron diversas actividades relacionadas con el funciona- 
miento estatal, estableciéndose una estructura de asentamientos que llegaron a constituir importantes instalaciones para: a) posibilitar el simple paso a otros puntos, b) el aprovisionamiento o el descanso de los contingentes, hasta c) una permanencia por tiempo mayor en función de tareas productivas, políticas y religiosas que inferimos tanto por las basuras alfareras como por la arquitectura remanente en las instalaciones (Urbina y González 2005; Uribe y Cabello 2005).

De este modo, en una primera categoría se encontrarían: a) la mayoría de los lugares con muy escaso material, poco erosionado y restringido a las más puras manifestaciones incaicas, destacando las foráneas, con características de depósito regular u homogéneo, cuyos desechos derivarían directamente de la circulación por el camino o de rituales vinculados al paso por la ruta (p.e., ofrendas). Una segunda categoría estaría compuesta por b) un número menor de unidades pero con una mayor cantidad de cerámica, combinando un importante porcentaje de alfarería clásica regional y del período Tardío, tanto incaica local como foránea. Aquí, además, tiende a aumentar el material erosionado, así como la heterogeneidad en el proceso de depositación, mostrando funcionalidades más diversas; sin embargo, todavía se trataría de actividades pasajeras relacionadas exclusivamente con el consumo de alimentos. En tercer lugar, se agrupan c) muy pocas unidades que se constituirían en la cabecera de este sistema, ya que la cantidad y variedad de materiales aumenta notablemente. Aquí es frecuente la asociación de escudillas incaicas locales con cántaros y ollas de la región, junto con materiales erosionados y el resto de las cerámicas incaicas y locales en contextos residenciales como públicos.

De este modo, en una primera categoría se encontrarían a) la mayoría de los lugares con muy escaso material, poco erosionado y restringido a las más puras manifestaciones incaicas, destacando las foráneas, con características de depósito regular u homogéneo, cuyos desechos derivarían directamente de la circulación por el camino o de rituales vinculados al paso por la ruta (p.e., ofrendas). Una segunda categoría estaría compuesta por b) un número menor de unidades pero con una mayor cantidad de cerámica, combinando un importante porcentaje de alfarería clásica regional y del período Tardío, tanto incaica local como foránea. Aquí, además, tiende a aumentar el material erosionado, así como la heterogeneidad en el proceso de depositación, mostrando funcionalidades más diversas; sin embargo, todavía se trataría de actividades pasajeras relacionadas exclusivamente con el consumo de alimentos. En tercer lugar, se agrupan c) muy pocas unidades que se constituirían en la cabecera de este sistema, ya que la cantidad y var- 
iedad de materiales aumenta notablemente. Aquí es frecuente la asociación de escudillas incaicas locales con cántaros y ollas de la región, junto con materiales erosionados y el resto de las cerámicas incaicas y locales en contextos residenciales como públicos.

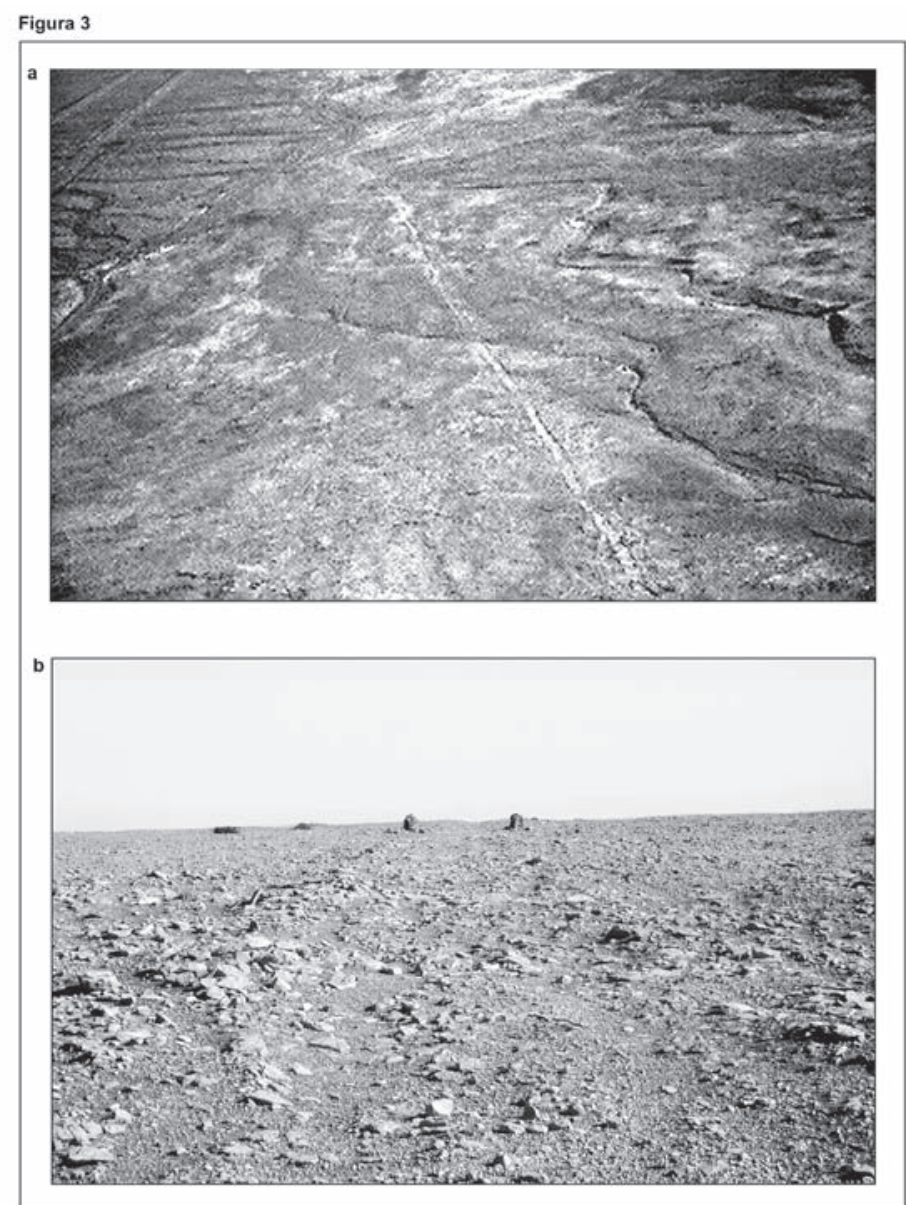

Figura 3a-b. Camino del Inka en el sector del Alto Loa (Norte de Chile). Vistas del tramo Lasana-Incahuasi (Berenguer et al. 2005).

Figure 3a-b. Inka road views at High Loa River (Northern Chile), between Lasana and Incahuasi points (Berenguer et al. 2005). 


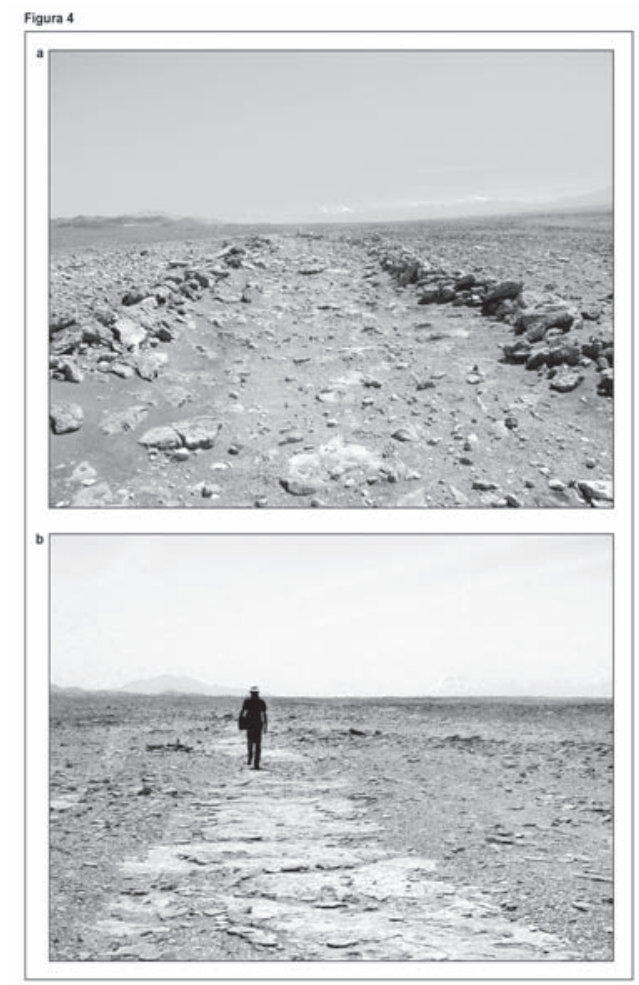

Figura 4a-b. Camino del Inka en el sector del Alto Loa (Norte de Chile). Vistas del tramo Incahuasi-Santa Bárbara (Fuente: Berenguer et al. 2005).

Figure 4a-b. Inka road views at High Loa River (Northern Chile), between Incahuasi and Santa Bárbara points (Berenguer et al. 2005).

En esta oportunidad, nuestro estudio se centra justamente en esta tercera categoría de asentamientos del Camino del Inka que caracterizan al alto Loa, partiendo del supuesto de que a través del análisis del comportamiento de la alfarería y sus desechos en contextos con arquitectura pública y residencial podremos profundizar en las dinámicas sociales y políticas que se gestaron con la presencia del Tawantinsuyo en esta parte de Atacama.

\section{La Cerámica del Camino incaico en el Alto Loa}

Siguiendo estos lineamientos, entonces, clasificamos el material y analizamos el comportamiento depositacional y espacial de la fragmentería cerámica del Alto Loa. Para el estudio de este material, contamos con muestras obtenidas por medio de recolecciones de superficie que se realizaron a partir de un muestreo al azar de los sitios (sobre el 10\%), tomando como referencia las estructuras arquitectónicas o recintos directamente asociados. 
A lo anterior se sumó la excavación dirigida de pozos de sondeo, cuadrículas y trincheras en ciertas estructuras, seleccionadas de acuerdo a los resultados de la evaluación in situ de los materiales en superficie y su arquitectura.

Este análisis ha comprendido la clasificación del material, la elaboración de bases de datos a partir de la tipología resultante, la selección de variables a estudiar a través de herramientas estadísticas básicas como conteos, porcentajes y frecuencias que han sido vertidos en tablas y gráficos. En primer lugar, la clasificación se ha basado en un reconocimiento visual y macroscópico de los fragmentos, cuyas características de pasta, tratamientos de superficie, forma, decoración y manufactura fueron comparados con las tipologías elaboradas para la zona (Varela 1992; Varela et al. 1993; Uribe 1994, 1996, 1997, 1999; Ayala y Uribe 1995). Específicamente, éstas ponen énfasis en los aspectos tecnológicos más que decorativos de la cerámica, lo cual se debe a que desde la aparición de la alfarería aquella es una práctica casi inexistente en el desierto de Atacama (Tarragó 1989). En este sentido, las pastas y el tratamiento de las superficies de las vasijas son los atributos más relevantes para la tipología, inmediatamente seguidos por el resto de las características, las que en su conjunto generan clases cerámicas que han sufrido transformaciones en el tiempo y en el espacio, permitiendo poner a la alfarería en secuencia histórica cultural (Orellana 1963; Le Paige 1964; Thomas et al. 1984; Berenguer et al. 1986; Tarragó 1989; Uribe 2002). Esto significa que a través de ellos es posible establecer las épocas representadas en los sitios, así como el origen local y foráneo de los mismos, a la vez que referirse a las dinámicas culturales asociadas (Castro et al. 1977, 1984; Uribe 1996, 1997, 1999; Agüero et al. 1997, 1999; Uribe y Carrasco 1999).

Para sistematizar estas observaciones, en una segunda fase se han construido las bases de datos donde se integra y ordena cuantitativamente toda la información tipológica sobre la base del número de fragmentos. En cuanto a ello, también se hacen apreciaciones conductuales sobre la manera como la alfarería quedó abandonada, la que es distinta según las circunstancias ocurridas, lo cual ayuda a tener una idea de las actividades que se desarrollaron en el sitio sincrónica y/o diacrónicamente, especialmente cuando existe información arquitectónica y estratigráfica complementaria. Esto se debe a que, gracias a las formas de las vasijas, la configuración de los tipos cerámicos revela cierta funcionalidad, lo cual es complementado con la abundancia o escasez de material (cantidad de tipos y fragmentos), así como la restaurabilidad, tamaño, desgaste o erosión y residuos de la fragmentería (p.e., hollín), entre otras variables (Adán 1995, 1996). Por esta razón, en una tercera etapa del trabajo se analiza la conducta del material a través de estadística descrip- 
tiva, correspondiente a la representación porcentual y gráfica de los tipos cerámicos en cada sitio, así como en relación con la distribución de éstos en las unidades de recuperación en particular. De acuerdo con lo anterior, hemos determinado un patrón tipológico general para todos los sitios que, en esta oportunidad, analizamos desde un enfoque más bien conductual y contextual (Schiffer 2002).

Dentro de este patrón general, se distinguió la presencia de un conjunto de tipos que configuran un componente temprano que se remontaría al Período Formativo del desierto de Atacama (ca. 1000 a.C.-500 d.C.), especialmente constituido por ejemplares locales que se extenderían desde momentos iniciales, medios y tardíos del Formativo hasta el Período Medio (ca. 500-950 d.C.), como lo señala la existencia de la peculiar alfarería monocroma y pulida de la región (Tarragó 1989; Sinclaire et al. 1998; Uribe y Ayala 2004). Por otra parte, registramos tipos de escudillas monocromas café, negras y pulidas junto con cuencos, cántaros y ollas, alisados como revestidos rojos, que serían característicos del desarrollo regional hasta más allá de la llegada del Inka (Uribe 1996, 1997, 2002), configurando un componente Loa-San Pedro propio del Intermedio Tardío del desierto de Atacama (ca. 950-1450 d.C.). Además de lo anterior, es posible distinguir ejemplares foráneos del mismo período constituidos por tipos monocromos de los Valles Occidentales ${ }^{2}$ y, principalmente, del Altiplano Meridional y el Noroeste Argentino, donde destacan estilos decorativos ampliamente reconocidos en la literatura especializada (Uribe 1996, 1997, 2002, 2004a).

Después, se distinguen ejemplares evidentemente foráneos del período Tardío que adscribimos al tipo Inka-Cusco o Cusco Policromo (Figura 5) con sus rombos e hileras de triángulos en negro, rojo y amarillo, ante, blanco o naranja (Valcárcel 1934; Rowe 1944). A esto se suman las expresiones incaicas locales de escudillas y aribaloides revestidas rojas (Figura 6 c-g; a, i, k), acompańados por expresiones semejantes (Figura 6 b, j, l; h), pero cuya tecnología refiere a un cambio productivo y más tardío identificado por sus "pastas con mica», a veces decorados (Uribe 1999). Asimismo, aparecen tipos incaicos provinciales como Inka-Pacajes o Saxámar con su decoración geométrica en negro sobre rojo de líneas onduladas y figuras esquemáticas de camélidos (Figura 7); Yavi-La Paya con decoración en negro, rojo y naranja de triángulos, espirales, reticulados y figuras ornitomorfas (Figura 8 a-e), e Inka-Diaguita con decoración de figuras antropomorfas y zoomorfas con ajedrezados y reticulados en negro y rojo sobre blanco (Figura $8 \mathrm{f}-\mathrm{g}$ ), los que provendrían del Altiplano Meridional, la Circumpuna y los Andes Meridionales (Uribe y Agüero 2003; Uribe y Cabello 2005). De esta ma- 
nera, se configuraría con claridad un componente Tardío (ca. 1450-1536 d.C.), que incorpora una serie de manifestaciones coherentes estilística y cronológicamente con la expansión del Tawantinsuyo hacia el desierto de Atacama. Luego, en el momento del contacto hispano hacia 1557 d.C. hasta la actualidad, determinamos la continuidad de la cerámica de "pastas con mica» en la región atacameña (Varela 1992; Uribe 2002), que configura el componente Etnográfico.

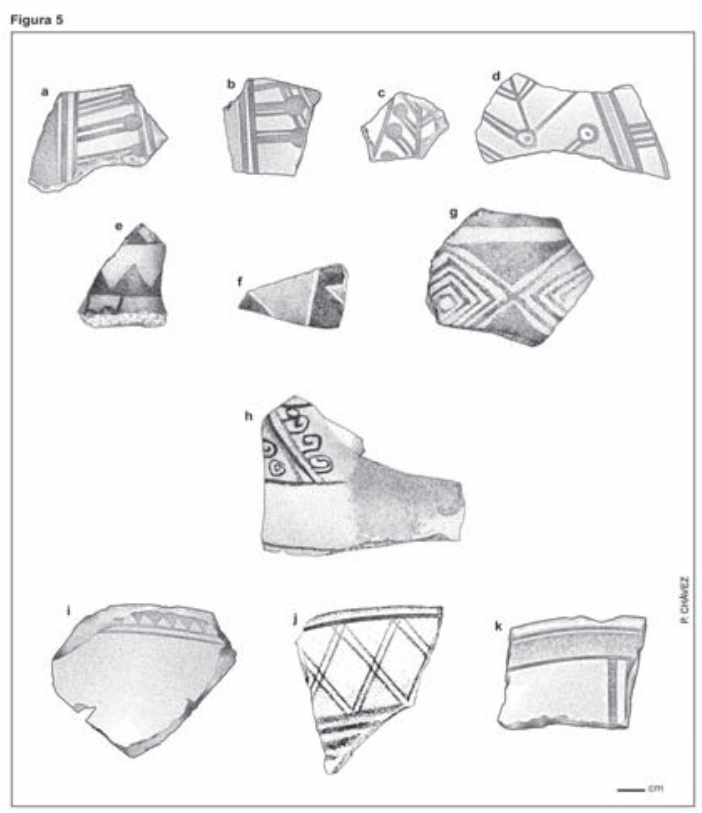

Figura 5. Fragmentos de cerámica Inka Cusco o Cusco Policromo (INK) del sector Alto Loa (Norte de Chile): a-d) Cusco Policromo A con espigas, e-g e i-j) Cusco Policromo $B$ con rombos y triángulos.

Figure 5. Pottery fragments of Inka Cusco or Cusco Polychrome type (INK) from Alto Loa (Northern Chile): a-d) Cusco Polychrome A with designs like spikes, e-g and i-j) Cusco Policromo $B$ with designs like rhomb and triangles. 


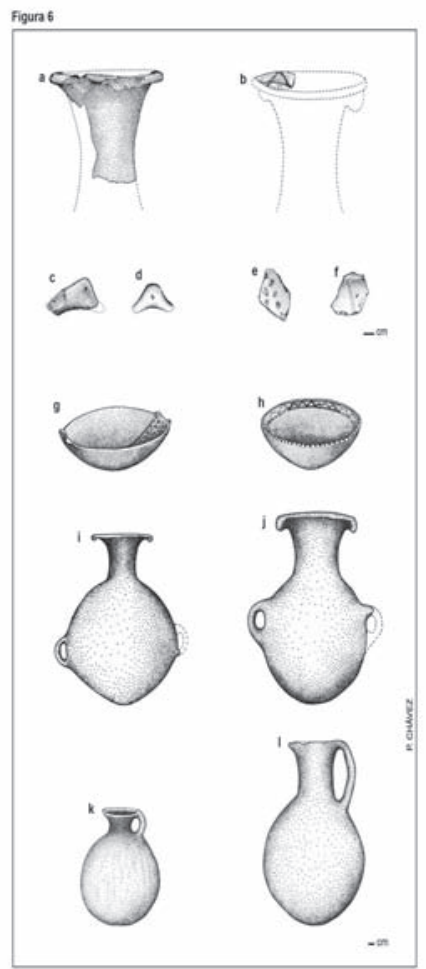

Figura 6. Fragmentos y piezas completas de cerámica Inka Local de la región del Loa Superior (Norte de Chile): c-g) Turi Rojo Revestido Pulido Ambas Caras (TPA); a, i y k) Turi Rojo Revestido Exterior-Negro Alisado Interior (TRN); b, j y l) Lasana Café Rojizo Revestido Exterior (LCE); h) Lasana Café Rojizo Revestido Pulido (LCP).

Figure 6. Fragments and complete pieces of Local Inca types from Upper Loa River Region (Northen Chile): $c-g$ ) Turi Slipped Red and Polished Both Faces (TPA); $a$, i and k) Turi Slipped Red-Smoothed Black (TRN); b, j and l) Lasana Sliped Reddish Brown (LCE); h) Lasana Slipped Reddish Brown and Polished (LCP). 


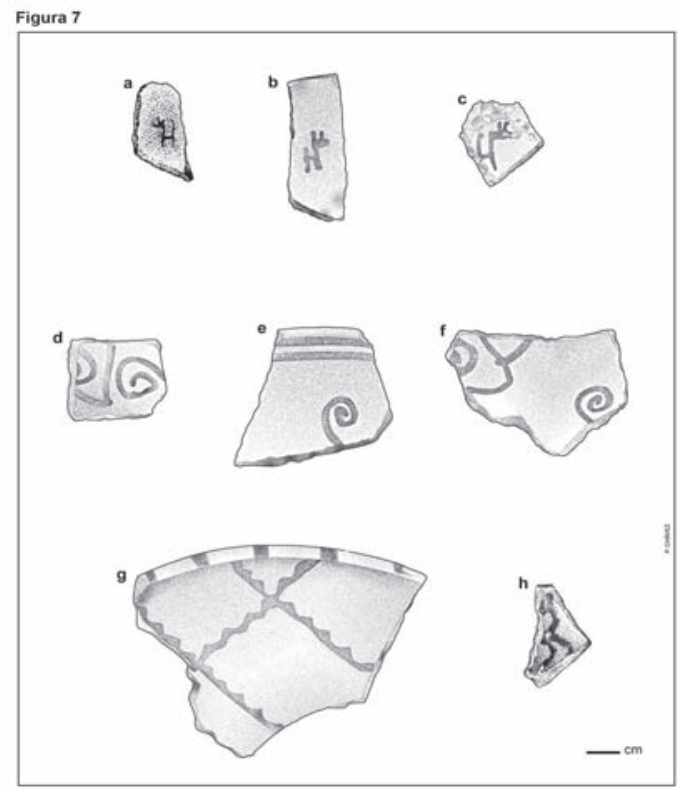

Figura 7. Fragmentos de cerámica altiplánica Inka-Pacajes o Saxámar (SAX) del sector Alto Loa (Norte de Chile): a-c) con figuras zoomorfas (camélidos), $d-f)$ con espirales, $g$-h) con lineas onduladas.

Figure 7. Pottery fragments of Inka-Pacajes or Saxámar types (SAX) from High Loa River (Northern Chile): a-c) with zoomorphic designs like camelids, $d-f$ ) with spiral lines, $g$-h) with waving lines.

Respecto a la discusión acerca de la temporalidad de todas estas expresiones cerámicas que nosotros reunimos en un gran componente (Stehberg 1991; Adamska y Micheczynski 1996; Pärssinen y Siiriäinen 1997), entendemos que la cronología absoluta del Estado Inca debe ser considerada como un problema no resuelto, siendo necesarios mayores antecedentes para intentar esclarecerlo. No obstante, siguiendo a Schiappacasse (1999), el análisis de los fechados absolutos en el núcleo incaico coincide en establecer una etapa pre-imperial entre el 1260 al 1396 d.C. y otra imperial del 1400 al 1518 d.C. En relación con esta última, se observarían tres peaks de fechas hacia el 1325, 1440 y 1600 d.C., sugiriendo una historia más compleja y temprana para la formación del Tawantinsuyo que la propuesta por la etnohistoria tradicional. En el caso de Chile y regiones aledañas, de acuerdo a un total de 80 fechados por termoluminiscencia y radiocarbono se observa una tendencia a ampliar el límite inferior de este proceso, pudiendo ubicarse este 
evento entre el 1400 y 1450 d.C. (Schiappacasse 1999). Frente a esta situación, utilizamos con cautela el concepto de expansión, el cual entendemos como un proceso de formación más que de conquista, y reunimos esta diversidad alfarera bajo el apelativo de componente Tardío y no propiamente Incaico debido a la complicada y diversa constitución de este crucial período de la arqueología andina. En suma, entendemos la formación del Tawantinsuyo como un lapso entre el 1400 y 1600 d.C., coherente con los fechados que presentamos en nuestro trabajo y el comportamiento estratigráfico de los sitios estudiados, donde los tipos cerámicos aquí definidos aparecen totalmente asociados (Tabla 1).

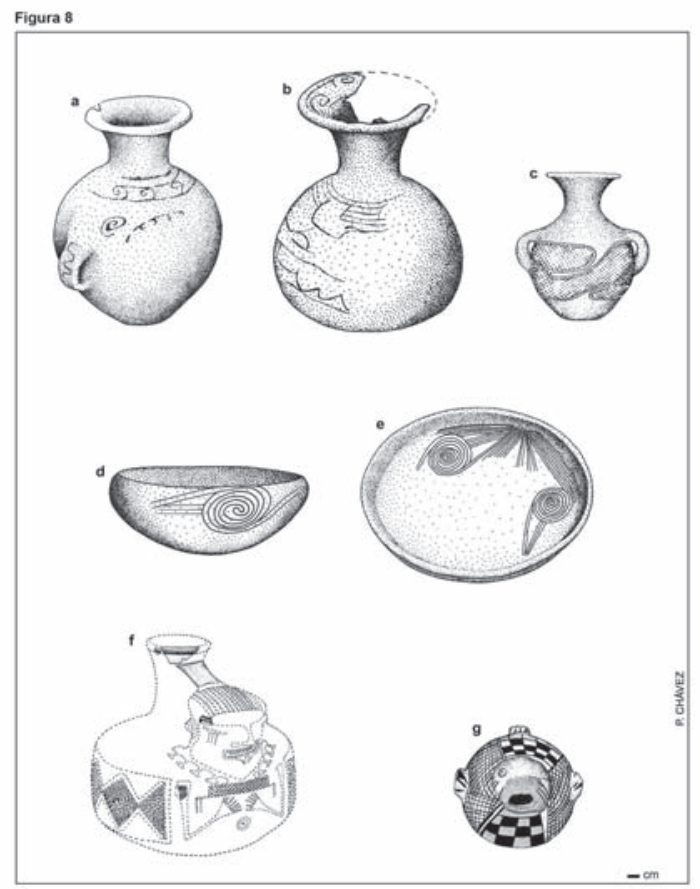

Figure 8. Fragmentos y piezas completas de cerámica Inka Provincial de la región del Loa Superior y San Pedro de Atacama (Norte de Chile): a-e) Yavi-La Paya del Noroeste Argentino (YAV), f-g) Diaguita-Inka del Norte Chico de Chile (DIA). Figure 8. Fragments and complete pieces of Inca Provincial types from Upper Loa River Region and San Pedro de Atacama (Northern Chile): a-e) Yavi-La Paya from Northwest Argentina (YAV), f-g) Diaguita-Inka from Semiarid Northern Chile (DIA). 


\begin{tabular}{|c|c|c|c|}
\hline FECHA & CERÁMICA & SITIO & NOMBRE \\
\hline $1340+/-60$ & SAX & $\mathrm{MI}-2$ & KONA KONA-2 \\
\hline $1385+/-50$ & DIA & LR-1 & INCAGUASI \\
\hline $1395+/-60$ & TRP & SBA-518 & ALDEA SBa-518 \\
\hline $1400+/-60$ & TRR & NA-7 & LEQUENA VIEJO \\
\hline $1445+/-45$ & TPA & CG-9 & BAJADA DEL TORO \\
\hline $1450+/-45$ & TRR & $\mathrm{MI}-1$ & KONA KONA-1 \\
\hline $1460+/-50$ & DUP & CG-9 & BAJADA DEL TORO \\
\hline $1480+/-50$ & INK & $\mathrm{MI}-2$ & KONA KONA-2 \\
\hline $1480+/-50$ & LCP & SBA-162 & CERRO COLORADO \\
\hline $1485+/-35$ & LCP & $\mathrm{MI}-2$ & KONA KONA-2 \\
\hline $1520+/-40$ & TRP & LR-1 & INCAGUASI \\
\hline $1540+/-35$ & INK & NA-7 & LEQUENA VIEJO \\
\hline $1545+/-45$ & TRP & SBA-518 & ALDEA SBa-518 \\
\hline $1555+/-35$ & TRB & Ml-1 & KONA KONA-1 \\
\hline $1565+/-40$ & TRP & SBA-518 & ALDEA SBa-518 \\
\hline $1565+/-40$ & TCA & SBA-162 & CERRO COLORADO \\
\hline $1570+/-40$ & INK & CG-9 & BAJADA DEL TORO \\
\hline $1570+/-40$ & INK & SBA-162 & CERRO COLORADO \\
\hline $1570+/-30$ & TGA & MI-1 & KONA KONA-1 \\
\hline $1585+/-40$ & INK & SBA-162 & CERRO COLORADO \\
\hline $1595+/-30$ & TCA & SBA-162 & CERRO COLORADO \\
\hline $1595+/-40$ & TCA & SBA-518 & ALDEA SBa-518 \\
\hline $1600+/-40$ & TPA & $\mathrm{MI}-2$ & KONA KONA-2 \\
\hline
\end{tabular}

Tabla 1. Cuadro con fechados por Termoluminiscencia de la cerámica incaica del Alto Loa (Proyecto FONDECYT 1010327).

Table 1. List of Thermoluminiscence Dates of Inka Pottery Types from Alto Loa (Project FONDECYT 1010327).

\section{Asentamientos y CerÁmica en el camino Incaico del Alto LoA}

Miño-1 y Miño-2 (3.810 y 3.932 metros sobre el nivel del mar). Miño-1 y Miño-2 corresponden a dos sitios separados por cerca de quinientos metros, aunque pertenecen a un mismo punto del Camino del Inka del Alto Loa (Figura 2) en plena cabecera o nacientes del río Loa (Berenguer et al. 2005).

Miño-1 (Mi-1), también denominado Kona Kona-1 (Castro 1992), estaría compuesto por al menos 36 estructuras arquitectónicas (Figura 9), de las cuales fueron analizadas sólo la 1, 2, 15 y 17 (11,1\% del sitio). Por su parte, Miño-2 (Mi-2), también denominado Kona Kona-2 (Castro 1992), se encontraría frente a Miño-1 y estaría compuesto por igual número de estructuras arquitectónicas (Figura 10), de las cuales fueron analizadas la 4, 5 , $13,19,20,21,26,27,29$ y 30 (29,4\% del sitio). A lo anterior se agrega un espacio abierto a modo de basural y sin asociación directa con las construcciones que fue cuadriculado y sistemáticamente recolectado. 


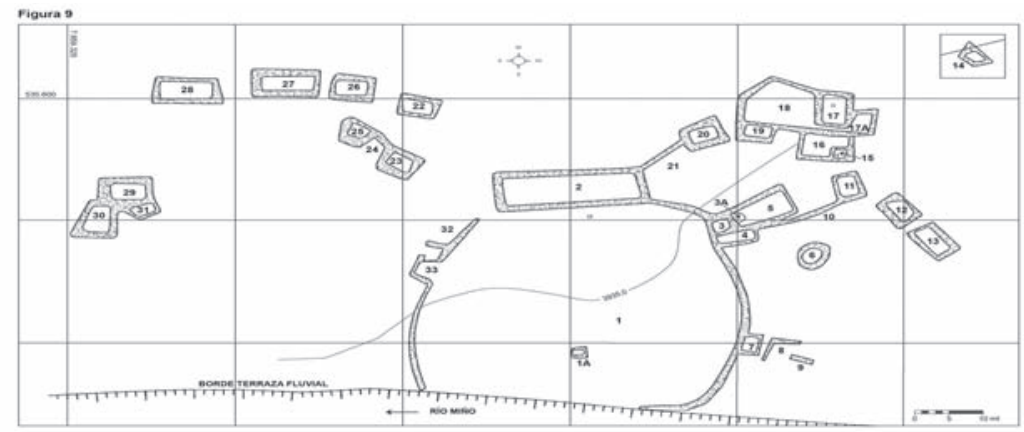

Figura 9. Plano taquimétrico y topográfico del sitio Miño-1, Alto Loa, con las principales estructuras mencionadas en el texto (gentileza de José Berenguer).

Figure 9. Miño-1 site settlement plan and elevations, High Loa River, and the most important structures included in the text (courtesy of José Berenguer).

Miño-1 (UTM E535646/N7659392), se ubica en la terraza occidental de un lecho seco y poco profundo que da origen al Loa. Unas 36 estructuras dispuestas en conglomerados o conjuntos dispersos sobre una meseta plana se distribuyen en un perímetro de 1,68 hectáreas incluyendo estructuras y espacios exteriores. La densidad edilicia proyectada (número de recintos por hectárea) señala una cifra de 20,8 recintos por hectárea de terreno, muy baja en comparación con un sitio aglutinado. En términos del uso del suelo e inversión arquitectónica, la sumatoria de las áreas internas de los recintos (es decir, los espacios delimitados por muros), alcanza un total de 2583,5 m², lo cual significa que de 1,68 hectáreas sólo fueron edificadas una parte cercana al 15\% de la superficie (Urbina y González 2005).

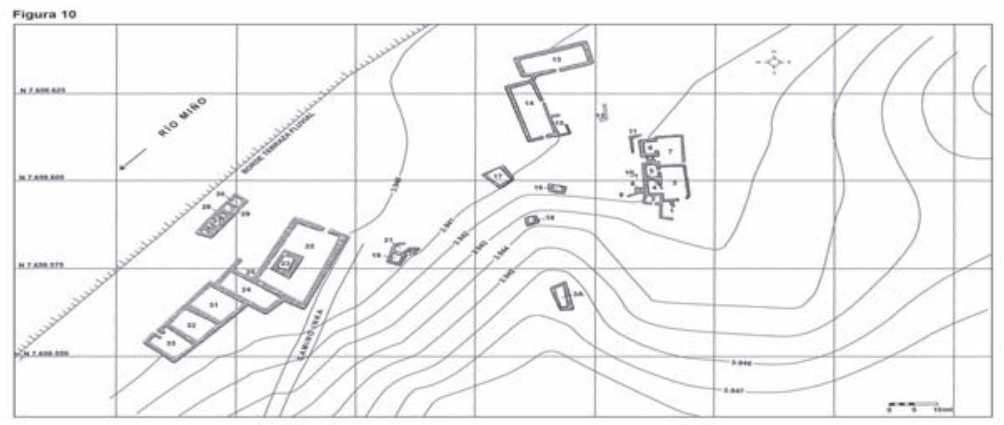

Figura 10. Plano taquimétrico y topográfico del sitio Miño-2, Alto Loa, con las principales estructuras mencionadas en el texto (gentileza de José Berenguer).

Figure 10. Miño-2 site settlement plan and elevations, High Loa River, and the most important structures included in the text (courtesy of José Berenguer). 
El material del sitio Mińo-1 suma 749 fragmentos de recolecciones superficiales y 91 de excavaciones, lo que en total constituye una muestra de 840 ejemplares divididos en un $89,2 \%$ de superficie y un 10,8\% de excavaciones. La cerámica predominante corresponde al Período Intermedio Tardío (22,9\%), siendo indicativa de las poblaciones locales de la región del Loa y San Pedro de Atacama. A lo anterior, se suma otra alfarería del Intermedio Tardío, pero posiblemente del Altiplano Meridional (0,1\%). Paralelamente, estos tipos aparecen junto con cerámica Tardía (12,5\%), tanto incaica local como aparentemente foránea, en especial del Altiplano Meridional (p.e., Inka-Pacajes o Saxámar). Por último, encontramos alfarería Etnográfica de períodos históricos en bajos porcentajes (2,5\%). Los erosionados constituyen más del $60 \%$ de la muestra total, señalando una importante alteración natural como antrópica de la cerámica del lugar.

Miño-2 (UTM E536023/N7659621), posee 36 estructuras dispuestas en cuatro conjuntos y otras dispersas en una ladera adyacente, demarcando un perímetro de 0,92 hectáreas, el cual incluye espacios exteriores y un segmento acotado del camino incaico que divide en dos a la instalación. Posee un patrón más aglutinado y ordenado que Miño-1, con una cifra de 39 recintos por hectárea de terreno. En términos del uso del suelo destinado a los edificios, la sumatoria de las áreas intramuros alcanza un total de 926,7 $\mathrm{m}^{2}$ lo que significa que del perímetro total sólo fueron construidos el 10\% del área total de asentamiento (Urbina y González 2005).

El material del sitio Miño-2 suma 4523 fragmentos de recolecciones superficiales y 401 de excavaciones, lo que en total constituye una muestra de 4924 ejemplares divididos en un $91,9 \%$ de superficie y un 8,1\% de excavaciones. La cerámica predominante corresponde al Período Intermedio Tardío (58\%), indicativa de las poblaciones locales de la región atacameña (Tabla 2). A ésta última se suma alfarería foránea del Intermedio Tardío con bastante seguridad del Altiplano Meridional (6,20\%), posiblemente también de los Valles Occidentales y del Noroeste Argentino (0,06\%). Sin embargo, igual que en Miño-1, estos tipos aparecen junto con cerámica Tardía $(12,8 \%)$, tanto incaica local como indudablemente foránea, en especial Cusco Policromo (1,6\%), además del aquella del Altiplano Meridional y del Noroeste Argentino. Por último, aparece una mínima presencia de alfarería Etnográfica de períodos históricos $(0,6 \%)$. Los erosionados constituyen más del $22 \%$ de la muestra total, señalando una alteración natural como antrópica más bien moderada de los fragmentos. 


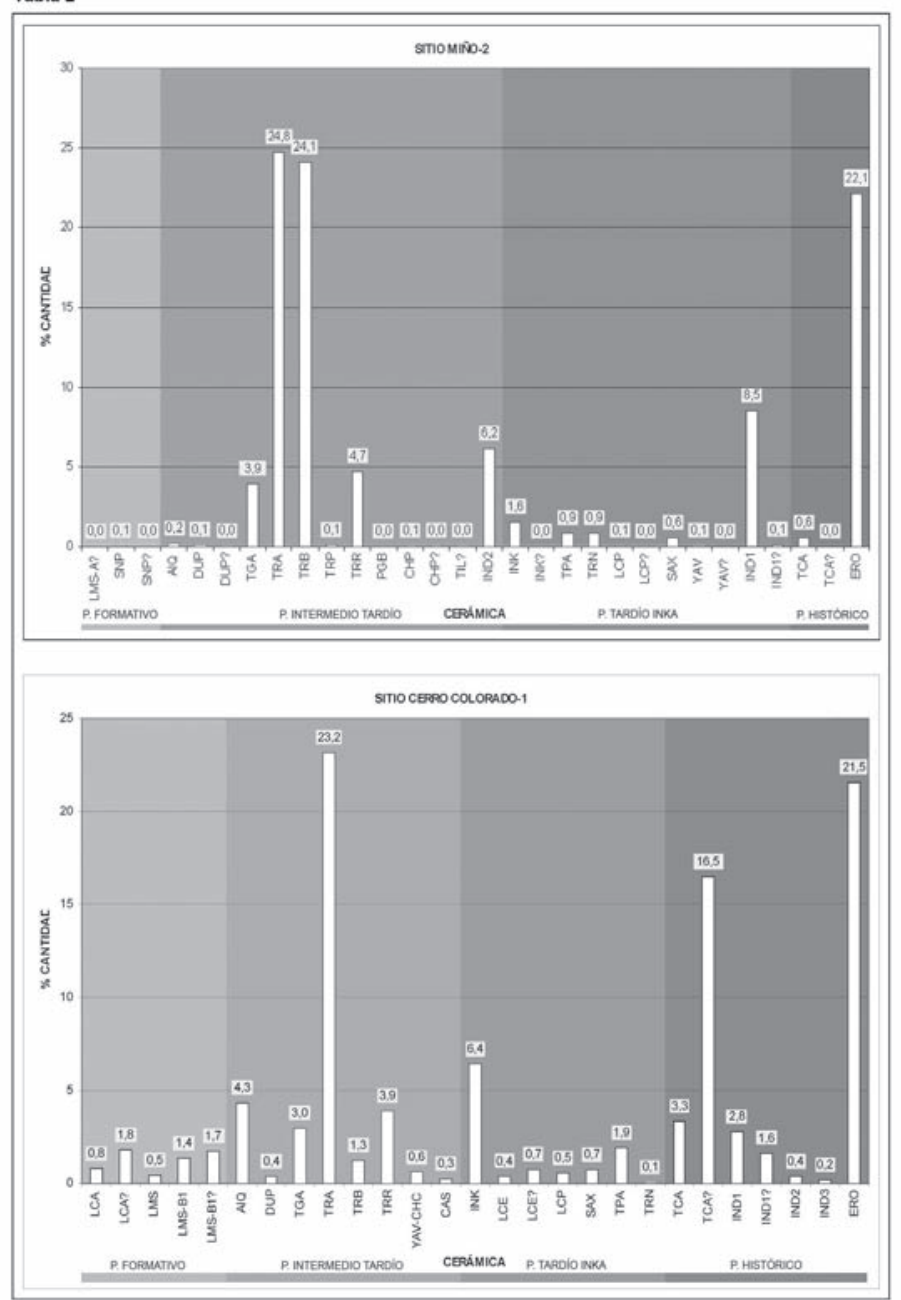

Tabla 2. Frecuencias y gráficos de cerámicas y periodos de los sitios Miño-2 y Cerro Colorado-1.

Table 2. Frequency of pottery debris and periods from Miño-2 and Cerro Colorado-1 sites.

Miño-1 registra escasez de material previo al Inka, relativa densidad de ocupación regional tardía y una leve a nula presencia histórica, lo cual es demostrativo de que el sitio y su actividad fueron iniciativas esencialmente imperiales. Durante esos momentos, un recinto a modo de plaza de 1940 $\mathrm{m}^{2}$ (Estructura 1) habría estado destinado a la producción a gran escala y almacenamiento estatal de alimentos, seguramente con fines residenciales pero sobre todo públicos y políticos, ligados a la vialidad del Camino del Inka y al entorno geográfico (p.e., minería), marcado por el volcán Miño y las nacientes del río Loa, en una zona de límites culturales entre el Altipla- 
no y Atacama. Con probabilidad, aquí se cocinaban y colmaban las vasijas que se repartían y empleaban en otros sectores del sitio o en los distintos asentamientos con fines altamente rituales. De hecho, recintos asociados a este patio (Estructura 2), estarían destinados al almacenamiento estatal por restos de grandes vasijas y en especial al consumo colectivo de alimentos preparados en el patio, apoyando los fines públicos y políticos. Por otra parte, existiría arquitectura menor (p.e., Estructuras 15 y 17), cuyas construcciones podrían identificar a unidades domésticas y/o familiares destinadas a mantener el funcionamiento de aquel sector del asentamiento; ya sea como espacio de almacenaje, especialmente de grandes contenedores, o lugar de cocina para una misma unidad doméstica por la concentración de restos de ollas.

El funcionamiento de Miño-1 como productor y lugar de almacenaje de comidas, bebidas así como de artefactos, sería complementario con el papel de Miño-2 en tanto lugar de acopio de esos líquidos y también de los desechos derivados de actividades colectivas, seguramente ceremoniales y públicas, donde se consumieron el alimento y la bebida obsequiados por el Inka (quizás desde Miño-1). Más aún, en el mismo Miño-2 debieron desarrollarse grandes festines empleando construcciones habitacionales mayores con techos a dos aguas a modo de callancas (Estructura 13), donde el uso colectivo de estos espacios sería coherente con las condiciones climáticas del lugar que por la gran altura obligan a una mayor protección. De esta manera, resulta consistente la formación de un basural en Miño-2, producto del aseo de esos edificios, demostrando a la vez la existencia de prácticas de limpieza sistemáticas durante el dominio del Tawantinsuyo a favor del despliegue público.

Otros espacios (p.e., Estructuras 4 y 5) pudieron formar sectores residenciales para la estadía de funcionarios estatales, a juzgar por la concentración de material cusqueño en espacios periféricos a las construcciones más grandes. Posiblemente, aquí residieron permanente o temporalmente quienes guardaron líquidos, cocieron alimentos y los consumieron, debido a cierta presencia de platos. Por lo tanto, se trataría de conjuntos arquitectónicos establecidos por el Tawantinsuyo, destinados al mantenimiento de funciones estatales, seguramente vinculadas con las actividades productivas de gran escala detectadas en Miño-1 y para servir en Miño-2. Paralelamente, un considerable número de construcciones de Miño-2 (p.e., Estructuras 19 a 21 y 26 a 30) indicarían utilizaciones del espacio con fines de almacenaje. En consecuencia, pareciera tratarse de arquitectura menor, en funcionalidad 
y escala, la que operaría de manera sincrónica y complementaria como bodegas o collcas (Castro 1992).

En definitiva, este conjunto arquitectónico de la cabecera del río Loa con escasez de material previo al Inka en estratigrafía, demostraría que sus depósitos y actividades fueron sobre todo estatales. A diferencia de Miño-1, esta actividad en Miño-2 alcanzó un carácter público, concentrándose aquí lo más fino e insinuando posibles oposiciones en términos duales de ambos sitios, en tanto lugar de cocina y lugar de banquetes respectivamente. Observamos, en consecuencia, una utilización diferencial del espacio construido dentro de una dinámica muy pautada o disciplinada, lo que sugiere un ejercicio de poder que con bastante certeza remite al modo de penetración del Estado incaico en Atacama (Uribe 2004b; Uribe y Adán 2004).

Cerro Colorado (3.262 metros sobre el nivel del mar). Cerro Colorado o Cirahue (SBa-162) corresponde a un punto intermedio del Camino del Inka en el tramo Lequena-Lasana (Figura 2), varios kilómetros al sur de Miño (Berenguer et al. 2005). Cerro Colorado (UTM N540032/E7585521), también denominado Cerro Colorado-1 (Castro 1992), estaría compuesto por al menos 66 recintos arquitectónicos, de los cuales fueron analizados la estructura 1, 1a, 4, 8, 10a, 12a, 17, 20, 20a, 23, 25, 35a, 41, 41a, 42, 42a y 43 , abarcando el $25,75 \%$ del sitio. La instalación completa comprende una superficie total intramuros de $4383 \mathrm{~m}^{2}$, la que se conforma a partir de tres grandes conjuntos de trazado ortogonal (Estructura 1 a 23a). Estos constituyen el sector incaico al norte del sitio y se conectan con el camino (Figura 11). Junto a estos conjuntos se aprecian estructuras dispersas consistentes en estructuras desmanteladas y parapetos hacia el sur, a las que se suman numerosas oquedades naturales en los afloramientos rocosos que presentan muros adosados y que probablemente fueron utilizadas como depósitos o alojamientos transitorios a modo de paskanas. Estas estructuras dispersas y en oquedades también se concentran en otro sector (Estructura 24 a 47) y son similares a aquellas ubicadas en la Circumpuna (Nielsen 1997). 


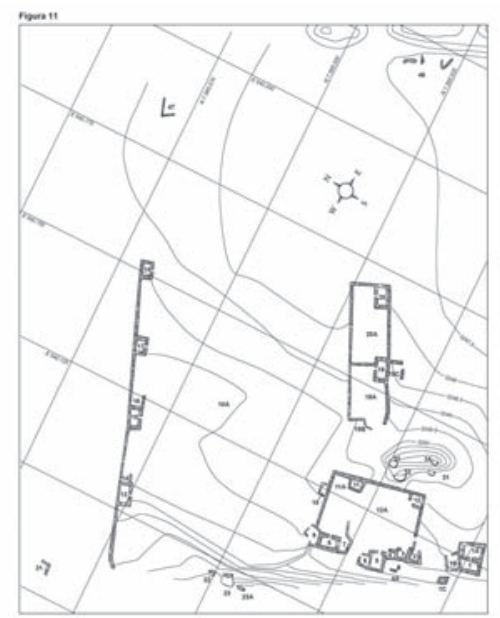

Figura 11. Plano taquimétrico y topográfico del sitio Cerro Colorado-1, Alto Loa, con las principales estructuras mencionadas en el texto, en particular la cancha y usno definidos por las estructuras $10 \mathrm{~A}$ y 23 (gentileza de José Berenguer).

Figure 11. Cerro Colorado-1 site settlement plan and elevations, High Loa River, and the most important structures included in the text, specially structures $10 \mathrm{~A}$ and 23 like cancha and usno (courtesy of José Berenguer).

El material cerámico de Cerro Colorado suma un total de 1110 fragmentos cerámicos, 989 de superficie y 110 de excavaciones, los que representan el $89,10 \%$ y $10,90 \%$ respectivamente. El material del Intermedio Tardío correspondiente a la alfarería del Loa y San Pedro es predominante $(36,58 \%)$, reuniendo más de un tercio de la cerámica del sitio (Tabla 2). Sin embargo, el componente Tardío implica alrededor de un 11\%. Por lo tanto, como en Miño-1 y Miño-2, mucho del material del Intermedio Tardío debió ser contemporáneo con el Inka, los que en su conjunto comprenderían cerca de la mitad de la alfarería analizada $(47,57 \%)$, representando la ocupación más importante del asentamiento. Lo anterior, es del todo coherente con el origen mayoritariamente superficial de los fragmentos (89,10\%). No obstante, aquí también se determinó la presencia de alfarería del Período Formativo que alcanzaría el 6,13\% de la muestra, si bien muchos de los ejemplares son dudosos. Por último, la cerámica Etnográfica representa un significativo 19,82\%. Los erosionados se acercan a un cuarto de la cerámica $(21,53 \%)$, señalando una alteración natural como antrópica de la alfarería idéntica a la de Miño.

Del mismo modo, el material de Cerro Colorado sugiere una presencia significativa y contemporánea de grupos poblacionales locales y foráneos 
en tiempos del Inka. Pero, además, habrían existido manifestaciones previas del Formativo, así como históricas aunque casi sin mayor continuidad en la actualidad. Ahora bien, centrándonos en el período Tardío y al revisar cada una de las construcciones estudiadas y sus depósitos, observamos un panorama bastante complejo que, como en Miño, refieren a una ocupación y utilización diferencial del espacio dentro de una dinámica muy pautada o disciplinada que sugiere un ejercicio de poder por parte del Inka en Atacama.

La ocupación incaica nuevamente manifiesta una dinámica bastante sofisticada y de escala pública en Alto Loa. En primer lugar, considerando las características de ciertos recintos (p.e., Estructuras 1 y 1a), permiten proponer la existencia de conjuntos habitacionales para funcionarios estatales del Tawantinsuyo, en los cuales se emplearía complementariamente el espacio arquitectónico. Unos para preparar y almacenar alimentos (Estructura 1), mientras otros fueron usados para el consumo de ellos (Estructura 1a). Esto se reproduciría en construcciones correspondientes a un espacio cerrado en torno al cual se organizan recintos más pequeños (Estructura 12a); de tal manera que actúa como un exterior o patio de los anteriores, donde se estarían desarrollando actividades preferentemente de consumo de alimentos y dejando basuras primarias de ello. Por su parte, en los interiores funcionaron otras labores exclusivas, livianas o en ausencia de cerámica como cocinas, bodegas, dormitorios, etc. (Estructuras 1, 4 y 8). En cualquier caso, la escasez de material, así como la casi nula presencia de desechos en los exteriores, indican que estos conjuntos arquitectónicos estuvieron afectos a prácticas de limpieza y/o tuvieron una ocupación pasajera, corta o temporal.

A diferencia de estos espacios domésticos y cotidianos, otro gran recinto con forma de U (Estructura 10a) permite definir un espacio colectivo y público a modo de plaza o cancha, con $3429 \mathrm{~m}^{2}$ de superficie. Podemos afirmar, entonces, que aquí se llevaron a cabo funciones referidas a la manutención de un lugar para la recepción e interacción entre personajes y objetos, tanto locales como foráneos, directamente relacionado con el Estado y las actividades festivas propiciadas por éste con sus consecuentes connotaciones políticas. Los personajes involucrados, seguramente, fueron de estatus bastante alto por las exóticas piezas que dejaron, correspondiente a uno de los porcentajes de cerámica Cusco Policromo más alto observado en la región $(6,57 \%)$.

De este modo, proponemos que el espacio de la plaza habría funcionado en términos de tres franjas de actividad debido a la distribución 
diferencial de restos de cántaros, ollas, platos y piezas exóticas (según una división en cuadrantes A, B y C-D). Una franja central y dos laterales, privilegiando la franja del medio (B) para el encuentro público festivo y ceremonial, mientras que a los lados quedarían las vasijas que surtían de alimentos y bebidas a los participantes que los consumían en el centro. Por tanto, es muy posible que los grandes contenedores se ubicaran cerca de los muros que es hacia donde se emplazan nuestros cuadrantes A y C-D, dejando un espacio central correspondiente al cuadrante $\mathrm{B}$ para la interacción social y el gran movimiento de cerámicas distintas. Las que, principalmente, estarían destinadas al servicio como consumo de comida y bebida, dentro de un ambiente especial dado por la alta concentración de cerámica incaica del Altiplano Meridional, Noroeste Argentino y sobre todo cusqueña. Además, es posible postular que en estos actos pudieron haber participado unidades sociales acotadas como lo sugiere la evidencia de pequeñas ollas en cada uno de los cuadrantes y franjas de actividad para calentar más que para preparar alimentos, las cuales por su acotada presencia remiten a eventos livianos y particulares. Por otra parte, el énfasis local y foráneo de los materiales dejan vislumbrar una diferencia a lo largo del eje Oeste-Este, pues hacia la izquierda los ejemplares incaicos claramente decrecen y se vuelven mayoritarios los locales; mientras que hacia la derecha es todo al revés, donde lo incaico se expresa en toda su magnificencia. Todo lo anterior es consistente considerando las amplias dimensiones de la estructura y su relación con recintos inmediatamente aledaños (Estructuras 17 y 20-20a), desde donde parecieran surtirse los alimentos consumidos en el lugar y quizás donde esta comida, así como las vasijas ocupadas para contenerla, eran almacenadas (p.e., cántaros, aribaloides, ollas y platos ornitomorfos).

En consecuencia, se distingue un gran ordenamiento espacial y funcional que resulta completamente coherente con la construcción, puesto que hacia el Oeste la plaza se halla cerrada y enfrentada a un especial recinto justo en el centro del muro y elevado sobre un afloramiento rocoso (Estructura 23), al contrario del Este donde aparece abierta. En este sentido, dicha estructura marcaría un eje para el movimiento dentro de la plaza, con divisiones duales (derecha-izquierda) y tripartitas (un centro y dos bordes) propias de la ideología imperial y que en este caso en particular refieren a la actividad pública del consumo festivo al mismo tiempo ceremonial como político de bebida y comida (Uribe 2004b; Uribe y Adán 2004). En conclusión, la estructura respondería a lo que tradicionalmente la etnohistoria relaciona a canchas y usnos dentro de la economía política del Tawantinsuyo (Zuidema 1980; Meddens 1997; Manríquez 1999; Pino 2004, 2005). 
Ahora, como en los otros casos, la relativa abundancia de material que a veces se hace muy escaso en ciertos sectores del recinto, sugieren una breve utilización de la plaza o -nos parece más correcto- dan cuenta de la realización de fuertes actividades de limpieza después de cada evento festivo, señalando que dicha operación no era continua. De este modo, aquí quedaron los fragmentos más pequeños que no estorbaban, muchos concentrados en los núcleos del área de actividad, siendo sometidos a una mayor meteorización por el pisoteo de considerables contingentes de personas. No obstante, para que estas limpiezas fueran practicadas se debió dejar un tiempo de pausa, por lo cual los eventos pudieron tener cierta periodicidad o calendario. En síntesis, la ocupación pudo ser alternada en el tiempo, pero muy intensiva, tanto que su limpieza no permitió la formación de depósitos estratigráficos, mostrando una acumulación de desechos principalmente horizontal.

Junto con los conjuntos residenciales, la plaza y sus estructuras complementarias que hemos identificado en Cerro Colorado, se hallan otras construcciones de distinto origen, cronología y/o funcionalidad. Para comenzar, la presencia de cerámica formativa concentrada en ciertas construcciones (p.e., Estructuras 1a, 10a, 42 y 42a) impiden realizar inferencias muy sólidas al respecto, salvo que confirmarían utilizaciones pasajeras del mismo sitio por poblaciones más tempranas que ocupaban desde mucho antes este espacio aunque de manera muy móvil, temporal, dispersa y/o por unidades sociales reducidas. De hecho, lo anterior es elocuente entre los pocos materiales de excavación que confirman el sustrato formativo en el sitio, alcanzando casi un quinto del depósito estratigráfico $(19,83 \%)$ y lo cual es evidente en la presencia esencialmente de restos de ollas, botellas o cántaros en conjunto con piezas lejanas y quizás especiales (p.e., del Noroeste Argentino). Lo anterior sugiere el desarrollo de ocupaciones domésticas las que, incluso, no serían tan livianas aunque sí acotadas, permitiendo inferir una presencia pasajera pero estable, quizás por una unidad familiar durante cierta temporada (p.e., asentamiento pastoril o estancia).

En tanto, otras construcciones (p.e., Estructuras 25 y 42), podrían haber funcionado como recintos habitacionales de grupos de paso por el lugar $y$, por consiguiente, vinculados a otras actividades móviles o temporales como pastoreo y caravanas, que serían característicos del Intermedio Tardío. $\mathrm{Al}$ respecto, las excavaciones permitieron distinguir ocupaciones propias del desarrollo regional, incluso superpuestas a las formativas; en principio de escala igualmente familiar pero mucho más pasajera, quizás enmarcadas dentro de esas prácticas pastoriles y caravánicas. Sin embargo, si los restos fueran contemporáneos con el Inka, también es posible pensar que se trata 
de contextos de grupos locales, familiares y modestos cumpliendo labores como pudo ser la mita a favor del Tawantinsuyo.

Otro conjunto constructivo (Estructuras 41, 41a, 42 y 42a), nos ofrece una dinámica distinta dentro de la misma ocupación incaica, cuyos escasos como pequeños materiales indicarían una pasajera aunque muy exclusiva utilización del lugar por ocupaciones propias del período Tardío, vinculadas directamente al Inka, el Altiplano Meridional y el Noroeste Argentino, sin evidenciar mayor continuidad histórica. En especial, se trataría de la existencia de un recinto habitacional complementario con otros vinculados a posibles funcionarios estatales del Tawantinsuyo, usados para preparar, consumir y almacenar alimentos. Pero, al mismo tiempo, cierta restaurabilidad de sus materiales indica un abandono rápido del lugar, lo que junto al destruido estado de las construcciones, insinúan el desmantelamiento de dicho espacio. Lo anterior, en consecuencia, también sugiere dos momentos de la ocupación tardía de Cerro Colorado dentro del período, ya que unas estructuras no siguieron en uso, inclusive se desarmaron, y otras se construyeron después, permaneciendo hasta hoy.

Finalmente, otro aspecto interesante, es que Cerro Colorado junto con ser una instalación ubicada a lo largo de la planicie o pampa que se extiende entre Miño y Lasana al occidente del río Loa, vinculada al movimiento de personas por su directa asociación al Camino del Inka (Berenguer et al. 2005), se constituye como un punto de encuentro de poblaciones. Esta situación, algo distinta a la de Miño, resulta destacable si se considera que alrededor de este punto se detectan pequeños poblados locales a modo de estancias agro-pastoriles y caravaneras, como los asentamientos SBa-41 y SBa518 (Berenguer 2004). Pero, también parece lógico porque en las cercanías se ha detectado el mineral de San José del Abra, donde fue identificado un complejo minero propio del período Tardío (AB-36), claramente explotado por el Inka (Núñez 1999; Salazar 2002).

\section{El INKa, LA CERÁmica y la ARQUiteCURA PÚblica del Alto LoA}

Recapitulando, las instalaciones primarias del Camino del Inka del Alto Loa expuestas en este reporte, igual como lo vimos antes en las postas de enlace entre ellas (Uribe y Cabello 2005), se caracterizarían por un comportamiento cerámico equivalente, cuyas diferencias permiten identificar particularidades entre un sector septentrional y otro meridional ${ }^{3}$. Pero además, apoyándonos en el registro arquitectónico, estamos en condiciones de plantear que sus peculiaridades responden a las políticas implementadas 
por el Tawantinsuyo, en concordancia con sus intereses estatales y la propia historia cultural de las poblaciones atacameńas del Alto Loa.

Los datos aportados por el estudio de la arquitectura de Miño y Cerro Colorado nos permiten avanzar en nuestras anteriores proposiciones sobre los asentamientos a la vera del camino imperial (Urbina y González 2005). Si bien habíamos indicado en términos de jerarquía funcional que Miño pertenecía a una categoría análoga a Cerro Colorado, correspondiente a instalaciones primarias y centros administrativos de los distritos mineros que articulaba la red vial de Alto Loa, notamos una inversión diferencial en los tipos y escala de la arquitectura pública presente en cada uno, la que debió servir a propósitos cívico-ceremoniales análogos pero en condiciones disímiles.

Por lo tanto, diseño y tamaño fueron criterios arquitectónicos selectivamente aplicados en la construcción y articulación jerárquica de las instalaciones incaicas, relacionando el tipo, escala y prestigio de las actividades cerámicas y sociales que debía realizarse en ellas y los usuarios pensados para habitarlas. Las superficies construidas por los incas en Miño (72 recintos $\left.=3510 \mathrm{~m}^{2}\right)$ y Cerro Colorado $\left(66\right.$ recintos $\left.=4383 \mathrm{~m}^{2}\right)$ fueron evidentemente las mayores de la red vial de Alto Loa (Berenguer et al. 2005). Por ejemplo, en términos de diseño, la cancha de Cerro Colorado $\left(3429 \mathrm{~m}^{2}\right)$ era un espacio abierto que ocupaba casi el doble del área de la plaza de Miño $\left(1940 \mathrm{~m}^{2}\right)$, y en vez de una callanca techada en un flanco, estaba delimitada al oeste por un afloramiento rocoso perpendicular a los muros laterales de casi cuatro metros de altura. Ambas soluciones, aunque distintas, generaban escenarios desde los cuales se tenía palco privilegiado a la imponente cadena de volcanes andinos, en Cerro Colorado una más inclusiva desde Miño a Panire y como telón de fondo el ojo de arena movediza del cerro Cirahue. Ambas plazas dejaron el extremo oriental sin construir o abierto, siguiendo un patrón en $U$, expuesto al naciente.

En este sentido, nos resulta elocuente que el Inka instaló en Miño la cabecera cívico-ceremonial de su sistema vial dentro del tramo estudiado, construyendo un asentamiento de gran jerarquía, equivalente a lo que sería Cerro Colorado en la mitad de la ruta. Ambos muestran la clara presencia de cerámica Cusco Policroma y un componente incaico notable, que en Miño supera el $12 \%$ de frecuencia y un $11 \%$ en Cerro Colorado. Así, a diferencia de Cerro Colorado que privilegia el espacio abierto de la plaza o cancha para el despliegue culinario, festivo y ceremonial, los sitios de Miño-1 y Miño-2 operarían de manera separada y complementaria, enfatizando el uso de es- 
pacios públicos techados o callancas, así como el complejo callanca-cancha empleado sobre todo en el norte del imperio (Hyslop 1990) y que sólo se repite en Turi y quizás en Catarpe Este, en pleno núcleo atacameño más al sur (Castro et al. 1993; Uribe et al. 2003).

En dichos asentamientos, esta actividad pública se tornaría política en tanto estaría vinculada con banquetes colectivos sugeridos por el comportamiento cerámico y donde se expresaría la avasalladora generosidad del Inka, distinguiéndose una ocupación y utilización diferencial del espacio construido dentro de una dinámica muy pautada o disciplinada que sugiere un ejercicio de poder íntimo pero a escala macrosocial (Foucault 2002). Establecidos estos puntos de alta jerarquía, de entrada y salida al norte como al sur del Alto Loa, el resto de asentamientos menores ubicados en puntos intermedios y en ambos tramos de la ruta (Uribe y Cabello 2005) cumplirían funciones complementarias en escala e intensidad como bisagras del sistema. De este modo, varios sitios constituirían instalaciones de apoyo a esa actividad, organizando la movilidad y el encuentro a través de diferentes lugares destinados a una estadía corta y aprovisionamiento de comida y bebida para aquellos que transitaban por el camino imperial. Lo cual, con seguridad, remite al modo andino de penetración del Estado incaico hacia el núcleo de Atacama a través del Alto Loa (Adán 1999; Adán y Uribe 2005; Uribe 2004b; Uribe y Adán 2004).

Considerando esto desde Mińo-Lequena, si bien se incluyó en toda la actividad vial a las poblaciones asociadas a la tradición cerámica Loa-San Pedro, de acuerdo a la preponderancia de su alfarería, pareciera que hacia el norte la ocupación incaica fue en gran medida obra exclusiva del Tawantinsuyo, coherente con la considerable frecuencia y fineza de la cerámica Cusco Policromo e Inka-Pacajes presente. Es decir, las poblaciones del Período Intermedio Tardío no habrían empleado esta ruta tan intensamente como sí pareciera darse en el tramo Lequena-Lasana, lo que se fortalece sólo de Lequena Viejo al sur donde se confirman evidencias del Formativo e incluso del Período Medio, repitiendo la conducta que el camino tiene desde aquí hasta el Despoblado de Atacama (Niemeyer y Rivera 1983). En suma, el sector septentrional no pareciera ser una ruta pastoril ni caravanera privilegiada por las poblaciones locales (Berenguer 2004). De hecho, aquí no se detectarían concentraciones humanas importantes para el imperio como más al sur. En cuyo caso, las instalaciones intermedias se intensificarían y vincularían de manera directa, incluso a través de bifurcaciones del camino, con poblados locales como pudo ser el caso de Bajada del Toro y Santa Bárbara-518, los que se extienden hasta ingresar al núcleo atacameño a través del Pucara de 
Lasana hasta Chiuchiu (Pollard 1982), seguramente reclutando la mano de obra necesaria por medio de la mita (Uribe et al. 2003; Uribe 2004b; Berenguer et al. 2005).

Lo anterior es, por otra parte, coincidente con el comportamiento de tradiciones alfareras y culturales foráneas presentes en el tramo Miño-Lequena. La relativa aunque significativa concentración de expresiones cerámicas del Altiplano Meridional, finas como corrientes, decoradas y no decoradas, e incluso posiblemente de los Valles Occidentales y en particular de Tarapacá, sugieren otra esfera de interacción, diferente a la de más al sur, donde tiende a manifestarse la alfarería del Noroeste Argentino, sobre todo Yavi-La Paya, e incluso de los Andes Meridionales como Inka-Diaguita (Uribe y Cabello 2005). Al respecto, nos parece que el Inka articuló este tramo del camino con poblaciones distintas, promoviendo la interacción cultural y económica de Atacama con esos territorios, completando así la ocupación por el norte, el oriente y el sur. De hecho, después del colapso del Tawantinsuyo todos estos sitios parecieran abandonarse rápidamente, retornando a la dinámica local, siendo reocupados sólo por leves incursiones estancieras (p.e., pastoriles o mineras), y en especial por la presencia histórica y seguro que luego republicana relacionada con el control de arriería y tráfico, concentradas en Lequena, Conchi y El Abra (Núñez 1999; Salazar 2002). De este modo, deja de haber lugares neutrales que privilegian el encuentro festivo en torno a la «generosidad» del Inka y, por el contrario, se potencia la centralización política que promueve la explotación indígena, insinuando un cambio ideológico que recién comenzamos a comprender desde la arqueología y la cerámica.

Frente a este panorama, todavía hipotético, aún hace falta la integración de más datos aportados por el resto de las materialidades (p.e., la evidencia lítica, arquebotánica, zooarqueológica, etc.), su asociación contextual y la solidez arqueométrica, imposibles de exponer por limitaciones de espacio. Sin embargo, en esta oportunidad hemos querido destacar que la articulación sistemática de la información cerámica y arquitectónica puede ofrecer una lectura que dota de contenido y entrega una imagen viva de las poblaciones ocupando los espacios construidos, permitiéndonos avanzar en las lógicas que el Inka desplegó para moverse y apropiarse de las tierras más áridas del Tawantinusuyo en los Andes Centro Sur.

Agradecimientos: A José Berenguer como investigador responsable del proyecto FONDECYT 1010327, al igual que a Diego Salazar por facilitarnos información de sus investigaciones en Conchi Viejo y Minera El 
Abra. Del mismo modo, a todos aquellos que participaron en estos estudios, particularmente a Gloria Cabello, Gregorio Calvo y Alejandra Sejas, por su valiosa ayuda e ideas en laboratorio. A Paulina Chávez por las ilustraciones. También agradecemos a los organizadores del IV Seminario de Arqueología UNFV, Claudia Arce, Claudio César Olaya y Marina Romero por invitarnos a Lima, donde fue originalmente expuesto este trabajo el año 2004.

Notas:

1 Proyecto FONDECYT 1010327 «Arqueología del sistema vial de los incas en el Alto Loa, II Región», dirigido por J. Berenguer, I. Cáceres, M. Uribe y C. Sanhueza.

2 Nos referimos principalmente a alfarería monocroma vinculada con los desarrollos culturales de la región arqueológica de Pica-Tarapacá, ubicada en el extremo meridional de los Valles Occidentales del norte de Chile (Uribe 2004a).

3 Esta situación sería coincidente con que el trazado de esta parte del camino iría principalmente por la banda oriental del río Loa, mientras que hacia el sur lo haría por el occidente (Berenguer et al. 2005).

\section{BiBLIOGRAFÍA}

Ad Amska, A. y A. Michecsynski. 1996. "Towards radiocarbon chronology of the Inca state". Boletín de la Misión Arqueológica Andina 1: 35-58.

Adán, L. 1995. "Diversidad funcional y uso del espacio en el Pukara de Turi”. Hombre y Desierto 9 (II):125-133.

Adán, L. 1996. Arqueología de lo cotidiano. Sobre diversidad funcional y uso del espacio en el Pukara de Turi. Memoria de Título en Arqueología. Departamento de Antropología, Universidad de Chile. Santiago.

Adán, L. 1999. "Aquellos antiguos edificios. Acercamiento arqueológico a la arquitectura prehispánica tardía de Caspana”. Estudios Atacameños 18: 13-33.

Adán, L. y M. Uribe. 2005. "El dominio inca en la localidad de Caspana: Un acercamiento al pensamiento político andino (río Loa, Norte de Chile)". Estudios Atacameños 29: 41-66.

Agüero, C., M. Uribe, P. Ayala y B. Cases. 1997. "Variabilidad textil durante el período Intermedio Tardío en el valle de Quillagua: una aproximación a la etnicidad”. Estudios Atacameños 14: 263-290.

Agüero, C., M. Uribe, P. Ayala y B. Cases. 1999. "Una aproximación arqueológica a la etnicidad: el rol de los textiles en la construcción de la identidad cultural en los cementerios de Quillagua (Norte de Chile)". Gaceta Arqueológica Andina 25: 167-197. 
Ayala, P. y M. Uribe. 1995. "Pukara de Lasana: revalidación de un sitio "olvidado" a partir de un análisis cerámico de superficie". Hombre y Desierto 9 (II): 135-145.

Berenguer, J. 2004. Caravanas, interacción y cambio en el Desierto de Atacama. Sirawe Ediciones. Santiago.

Berenguer, J., I. Cáceres, C. Sanhueza y P. Hernández. 2005. "El Qhapaqñan en el Alto Loa, norte de Chile. Un estudio micro y macromorfológico". Estudios Atacameños 29: 7-39.

Berenguer, J., A. Deza, A. Román y A. Llagostera. 1986. "La secuencia de Myriam Tarragó para San Pedro de Atacama: un test por termoluminiscencia”. Revista Chilena de Antropología 5: 17-54.

Castro, V. 1992. "Nuevos registros de la presencia Inka en la provincia de El Loa, Chile". Gaceta Arqueológica Andina 21 (VI): 139-154.

Castro, V.; C. Aldunate y J. Berenguer. 1984. "Orígenes altiplánicos de la fase Toconce”. Estudios Atacameños 7: 209-235.

Castro, V.; J. Berenguer y C. Aldunate. 1977. "Antecedentes de una interacción altiplano-área atacameña durante el período Tardío: Toconce". Actas del VII Congreso de Arqueología Chilena, tomo II: 477-498. Altos de Vilches.

Castro, V., F. Maldonado y M. Vásquez. 1993. "Arquitectura del "Pukara de Turi”. Boletín del Museo Regional de La Araucania 4 (II): 79-106.

Foucault, M. 2002. Vigilar y castigar: el nacimiento de la prisión. Siglo Veintiuno Editores. Buenos Aires.

Hyslop, J. 1990. Inka settlement planning. University of Texas Press, Austin.

Latcham, R. 1928. La prehistoria chilena. Sociedad Impresora y Litográfica Universo. Santiago.

Le Paige, G. 1964. "El precerámico en la cordillera Atacameña y los cementerios del periodo agroalfarero de San Pedro de Atacama". Anales de la Universidad del Norte 3, 275 pp.

Manríquez, V. 1999. "El término Ylla y su potencial simbólico en el Tawantinsuyu. Una reflexión acerca de la presencia inca en Caspana (río Loa, desierto de Atacama)". Estudios Atacameños, 18: 107-118.

Meddens, F. 1997. "Function and meaning of the usnu in Late Horizon Peru". Tawantinsuyu, 3: 5-14. 
Nielsen, A. 1997. "Inkas en Lípez: primera aproximación". Ponencia presentada en el simposio El Estado Inka: Desde la periferia al epicentro, XII Congreso Nacional de Arqueología Argentina. Universidad Nacional de La Plata, Octubre, La Plata.

Niemeyer, H. y M. Rivera. 1983. "El camino del inca en el despoblado de Atacama". Boletín de Prehistoria de Chile 9: 91-193.

Núńez, L. 1999. "Valorización minero-metalúrgica circumpuneña: Menas y mineros para el Inka rey”. Estudios Atacameños 18: 177-221.

Núńez, L. y T. D. Dillehay. 1979. Movilidad giratoria, armonía social y desarrollo en los Andes Meridionales: patrones de tráfico e interacción económica. Universidad del Norte. Antofagasta.

Orellana, M. 1963. "Problemas de la arqueología de San Pedro de Atacama y sus alrededores". Anales de la Universidad del Norte, 2: 27-39.

Pärssinen, M. y A. Siiriäinen. 1997. "Inca-style ceramics and their chronological relationship to the inca expansion in the southerb lake Titicaca area (Bolivia)". Latin American Antiquity 8 (3): 255-272.

Pino, J. L. 2004. "El Ushnu inka y la organización del espacio en los principales tampus de los wamani de la sierra central del Chinchaysuyu". Chungara 36 (2): 303-311.

Pino, J. L. 2005. "El ushnu y la organización espacial astronómica en la sierra central del Chinchaysuyu". Estudios Atacameños 29: 143-161.

Pollard, G. 1982(1970). The cultural ecology of ceramic stage settlement in Atacama desert. Tesis doctoral. Columbia University. Ann Arbor.

Rowe, J. 1944. "An introduction to the archaeology of Cusco". Papers of the Peabody Museum of American Archaeology and Ethnology, XXVII (2): $69 \mathrm{pp}$.

Salazar, D. 2002. Introducción a la minería prehispánica. El complejo minero San José del Abra, II Región, 1450-1536 d.C. Tesis de Magíster en Arqueología. Departamento de Antropología, Universidad de Chile. Santiago.

Schiapacasse, V. 1999. "Cronología del Estado Inca”. Estudios Atacameños 18: 133-140.

Schiffer, M. 2002. Behavioral archaeology. Percheron Press. Albuquerque. 
Sinclaire, C.; M. "La alfarería del período Formativo en la región del Loa Superior: sistematización y tipología". Contribución Arqueológica 5 (II): 285-314.

Stehberg, R. 1991. "El límite inferior cronológico de la expansión incaica en Chile". Xama, 4-5: 63-89.

Tarragó, M. 1989. Contribución al conocimiento arqueológico de las poblaciones de los oasis de San Pedro de Atacama en relación con los otros pueblos puneños, en especial del sector septentrional del Valle Calchaqui. Tesis de Doctorado en Historia. Universidad Nacional de Rosario. Rosario.

Thomas, C.; C. Massone y A. Benavente. 1984. "Sistematización de la alfarería del área de San Pedro de Atacama”. Revista Chilena de Antropología 4: 49-119.

Uhle, M. 1919. "La arqueología de Arica y Tacna". Boletín de la Sociedad Ecuatoriana de Estudios Históricos Americanos III (7-8): 1-48.

Urbina, S. y C. González. 2005. "Asentamientos tardíos en el camino Inka de Alto Loa: análisis arquitectónico de las instalaciones en el tramo Lasana-Miño". Informe de avance proyecto Fondecyt 1010327, Conicyt, Santiago.

Uribe, M. 1994. La cerámica arqueológica de Santa Bárbara: contextos de pastores-caravaneros en la subregión del Alto Loa (1200-1480 d.C.). Informe de Práctica Profesional. Departamento de Antropología, Universidad de Chile. Santiago.

Uribe, M. 1996. Religión y poder en los Andes del Loa: una reflexión desde la alfarería (periodo Intermedio Tardio). Memoria de Título en Arqueología. Departamento de Antropología, Universidad de Chile. Santiago.

Uribe, M. 1997. "La alfarería de Caspana en relación a la prehistoria tardía del subárea circumpuneña”. Estudios Atacameños 14: 243-262.

Uribe, M. 1999. "La alfarería inca de Caspana (norte de Chile)". Boletín de la Sociedad Chilena de Arqueología 27: 11-19.

Uribe, M. 1999-2000. "La arqueología del Inka en Chile”. Revista Chilena de Antropología 15: 63-97.

Uribe, M. 2002. "Sobre alfarería, cementerios, fases y procesos durante la prehistoria tardía del desierto de Atacama (800-1600 d.C.)". Estudios Atacameños 22: 7-31. 
Uribe, M. 2004a. Alfarería y metodología. Aportes y proyecciones de los estudios cerámicos en la arqueología del Norte Grande de Chile. Tesis de Magíster en Arqueología. Facultad de Ciencias Sociales, Universidad de Chile. Santiago.

Uribe, M. 2004b. "El Inka y el poder como problemas de la arqueología del Norte Grande de Chile". Chungara 36 (2): 313-324.

Uribe, M. y L. Adán. 2004. "Acerca del dominio Inka, sin miedo, sin vergüenza”. Chungara, Volumen Especial I: 467-480.

Uribe, M., L. Adán y C. Agüero. 2003. "El dominio del Inka, identidad local y complejidad social en las tierras altas del desierto de Atacama, Norte Grande de Chile (1450-1541 d.C.)”. Boletín de Arqueología PUCP 6: 301-336.

Uribe, M. y C. Agüero. 2004. "Aproximaciones a la Puna de Atacama y la Problemática Yavi”. Ponencia presentada en el XVI Congreso Nacional de Arqueología Chilena. Sociedad Chilena de Arqueología, Octubre 2003, Tomé, Concepción.

Uribe, M. y P. Ayala. 2004. "La alfarería de Quillagua en el contexto formativo del Norte Grande de Chile (1000 a.C.-500 d.C.)". Chungara, Volumen Especial II: 585-597.

Uribe, M. y G. Cabello. 2005. "Cerámica en el camino: los materiales del río Loa (Norte Grande de Chile) y sus implicancias tipológicas y conductuales para la comprensión de la vialidad y expansión del Tawantinsuyo". Revista Española de Antropología Americana 35: 75-98.

Uribe, M. y C. Carrasco. 1999. "Tiestos y piedras talladas de Caspana: La producción alfarera y lítica en el Período Tardío del Loa Superior". Estudios Atacameños 18: 55-71.

Valcárcel, L. 1934. "Sajsawaman redescubierto". Revista del Museo Nacional III (1-2): 3-36.

Varela, V. 1992. De Toconce, pueblo de alfareros, a Turi, pueblo de gentiles. Memoria de Título en Arqueología. Departamento de Antropología, Universidad de Chile. Santiago.

Varela, V.; M. Uribe y L. Adán. 1993. "La cerámica arqueológica del sitio "Pukara" de Turi: 02-Tu-002". Boletín del Museo Regional de La Araucanía 4 (2): 107-122. 
Villaseca, M. de los A. 1998. Entre Luces y Sombras. Etnoarqueología de Pastores del Alto Loa. Memoria de Título. Departamento de Antropología, Facultad de Ciencias Sociales, Universidad de Chile. Santiago.

Zuidema, T. 1980. "El ushnu". Revista de la Universidad Complutense 28 (117): 317-362. 